\title{
In reply: Pain exposure physical therapy in complex regional pain syndrome: promising enough to warrant further investigation
}

\author{
Daniela Bravo, MD · Silvia Duong, BScPhm, PharmD • Keith J. Todd, MD, PhD, CCFP • \\ Roderick J. Finlayson, MD, FRCPC $・$ D. Q. Tran, MD, FRCPC $\mathbb{D}$
}

Received: 25 April 2018/Accepted: 25 April 2018/Published online: 12 July 2018

(C) Canadian Anesthesiologists' Society 2018

\section{To the Editor,}

We thank Dr. Staal et al. ${ }^{1}$ for their interest in our review article $^{2}$ on complex regional pain syndrome (CRPS) and for bringing to our attention a trial that had escaped the literature search. ${ }^{3}$

We have read the three trials ${ }^{3-5}$ discussed by Staal et al. ${ }^{1}$ and would like to present readers with a more cautious interpretation. First, in Barnhoon et al.'s study, an intention-to-treat analysis clearly showed no benefit associated with pain exposure physical therapy (PEPT) compared with conventional treatment. ${ }^{4}$ Staal et al. ${ }^{1}$ argue that more "nuanced" (i.e., positive) findings could be derived from a per protocol analysis. We respectfully disagree as the scientific gold standard remains intentionto-treat and not per protocol analysis. ${ }^{6}$ In fact, introducing the latter confers inherent bias (rather than "nuance"), particularly as the authors might not have conducted a per protocol analysis had the intention-to-treat analysis revealed a treatment effect. For example, in Barnhoon et al.'s secondary analysis of the healthcare costs incurred during the first nine months of treatment, ${ }^{5}$ the intention-totreat analysis revealed that conventional treatment was $64 \%$ more expensive than PEPT. This led the authors to

\section{Bravo, MD}

Department of Anesthesia, Hospital Clínico Universidad de Chile, University of Chile, Santiago, Chile

S. Duong, BScPhm, PharmD · K. J. Todd, MD, PhD, CCFP Jewish General Hospital, Herzl Family Medicine Center Montreal, Montreal, QC, Canada

R. J. Finlayson, MD, FRCPC · D. Q. Tran, MD, FRCPC ( $)$ Department of Anesthesia, Montreal General Hospital, McGill University, Montreal, QC, Canada

e-mail: de_tran@hotmail.com immediately conclude that cost differences favour PEPT without resorting to the "nuanced" per protocol analysis to confirm or disprove these findings. Second, den Hollander et $a l^{2}$ have indeed reported that, compared with conventional treatment, exposure in vivo resulted in decreased self-reported disability, pain intensity, pain catastrophizing, perceived harmfulness of activities, and increased health-related quality of life. However, den Hollander et $a .^{3}{ }^{3}$ specifically recruited subjects with documented pain-related fear, whereas Barnhoon et al. ${ }^{4}$ did not triage for such a subset of patients. Despite this important distinction, Staal et al. ${ }^{1}$ draw a parallel between the two trials because they "share the theory of exposure to pain and stimulated use of the affected limb". Such an argument is flawed-it would be akin to stating that, since root canal therapy is indicated for dental cavities complicated by abscesses, it should also be performed for all cavities.

In summary, based on our reading of the literature, we respectfully disagree with the assertion that PEPT "deserves a place in the treatment of CRPS". We concede that the current evidence supports its role in patients with pain-related fear. However, the available trials do not (yet) support its use in other subsets of CRPS patients. Nonetheless, they highlight the need for further randomized investigation with proper intention-to-treat analysis.

Conflicts of interest None declared.

Editorial responsibility This submission was handled by Dr. Hilary P. Grocott, Editor-in-Chief, Canadian Journal of Anesthesia. 


\section{References}

1. Staal JB, Klomp FP, Nijhuis-van der Sanden MW. Pain exposure physical therapy in complex regional pain syndrome: promising enough to warrant further investigation? Can J Anesth 2019; 66. DOI: https://doi.org/10.1007/s12630-018-1174-3.

2. Duong S, Bravo D, Todd KJ, Finlayson RJ, Tran DQ. Treatment of complex regional pain syndrome: an updated systematic review and narrative synthesis. Can J Anesth 2018. DOI: https://doi.org/ 10.1007/s12630-018-1091-5.

3. den Hollander $M$, Goossens $M$, de Jong $J$, et al. Exposure or protect? A randomized controlled trial of exposure in vivo vs pain contingent treatment as usual in patients with complex regional pain síndrome type 1. Pain 2016; 157: 2318-29.
4. Barnhoorn KJ, van de Meent H, van Dongen RT, et al. Pain exposure physical therapy (PEPT) compared to conventional treatment in complex regional pain syndrome type 1: a randomised controlled trial. BMJ Open 2015; 5: e008283.

5. Barnhoorn K, Staal JB, van Dongen RT, et al. Pain exposure physical therapy versus conventional treatment in complex regional pain syndrome type 1-a cost-effectiveness analysis alongside a randomized controlled trial. Clin Rehabil 2018. DOI: https://doi.org/10.1177/0269215518757050.

6. McCoy CE. Understanding the intention-to-treat principle in randomized controlled trials. West J Emerg Med 2017; 18: 1075-8. 